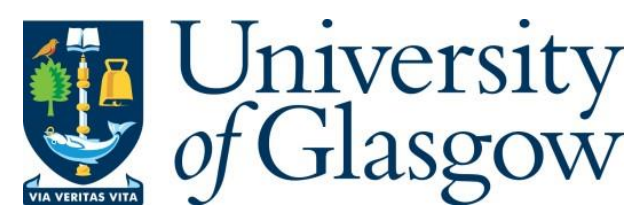

El-Shinawi, H., Cussen, E. J. and Corr, S. A. (2018) Selective and facile synthesis of sodium sulfide and sodium disulfide polymorphs. Inorganic Chemistry, 57(13), pp. 7499-7502.

There may be differences between this version and the published version. You are advised to consult the publisher's version if you wish to cite from it.

$\underline{\text { http://eprints.gla.ac.uk/165014/ }}$

Deposited on: 7 September 2021

Enlighten - Research publications by members of the University of Glasgow http://eprints.gla.ac.uk 


\title{
A selective and facile synthesis of sodium sulfide and sodium disulfide polymorphs
}

\author{
Hany El-Shinawi, ${ }^{\ddagger}$ Edmund J. Cussen ${ }^{\dagger}$ and Serena A. Corr ${ }^{\ddagger}{ }^{*}$ \\ ‡ School of Chemistry, WestCHEM, University of Glasgow, Glasgow G12 8QQ, UK. \\ ${ }^{\dagger}$ Department of Pure and Applied Chemistry, WestCHEM, The University of Strathclyde, Glasgow, G1 1XL, UK. \\ KEYWORDS. Sodium sulfide, sodium disulfide, lithium sulfur battery, microwave synthesis.
}

\section{Supporting Information}

\begin{abstract}
Na}_{2} \mathrm{~S}$ and $\mathrm{Na}_{2} \mathrm{~S}_{2}$ were selectively synthesized using a microwave-assisted thermal treatment of a $\mathrm{Na}^{+} / \mathrm{S}$ solution in tetraglyme between $100{ }^{\circ} \mathrm{C}$ and $200{ }^{\circ} \mathrm{C}$, considerably lower than current routes. This novel synthetic pathway yields the $\mathrm{Na}_{2} \mathrm{~S}$ phase in high purity and allows for good selectivity between the polymorphs of $\mathrm{Na}_{2} \mathrm{~S}_{2}$ ( $\alpha$ - and $\beta$-phases). These materials show promising electrochemical properties and are particularly interesting for the continued development of $\mathrm{Na}$ $\mathrm{S}$ batteries.
\end{abstract}

High purity sodium sulfide and polysulfides are key reactants in a range of organic and inorganic processes, with applications across industry including dye manufacture, textiles and the synthesis of organic intermediates. Industrially, $\mathrm{Na}_{2} \mathrm{~S}$ is prepared by carbon reduction of $\mathrm{Na}_{2} \mathrm{SO}_{4}$. On the laboratory scale, a reaction between elemental $\mathrm{Na}$ and $\mathrm{S}$ is typically carried out. The former synthesis requires temperatures of between $600{ }^{\circ} \mathrm{C}$ and $1100{ }^{\circ} \mathrm{C}$ and produces $\mathrm{CO}_{2}$ as a by-product, according to the reaction $\mathrm{Na}_{2} \mathrm{SO}_{4}+2 \mathrm{C} \rightarrow \mathrm{Na}_{2} \mathrm{~S}+2 \mathrm{CO}_{2} \cdot{ }^{1}$ The reaction between $\mathrm{Na}$ and $\mathrm{S}\left(2 \mathrm{Na}+\mathrm{S} \rightarrow \mathrm{Na}_{2} \mathrm{~S}\right.$ ), on the other hand, is performed in liquid ammonia and requires extreme precautions due to the hazardous nature of some of these reactants. ${ }^{2} \mathrm{Na}_{2} \mathrm{~S}$ and sodium polysulfides may also be accessed by the reaction between $\mathrm{Na}$ and $\mathrm{S}$, either by a direct molten reaction or in dimethoxyethane in the presence of catalytic aromatic hydrocarbons..$^{-5}$ These techniques offer a good degree of selectivity; however, they do not avoid the use of elemental $\mathrm{Na}$ which again presents a considerable hazard. Beyond the carboreduction of $\mathrm{Na}_{2} \mathrm{SO}_{4}$, Na-metal free syntheses are limited to drying hydrous sodium sulfide which is both time and energy consuming due to the requirements of several heat treatments under controlled pressure. With the considerable use of these materials in industrial processes and their potential for applications in energy storage, there is a pressing need to develop new chemistries to access these compounds through more benign routes. Here, we report a novel and facile synthesis that avoids the use of elemental $\mathrm{Na}$ and produces high purity materials at low cost and at temperatures not exceeding $200{ }^{\circ} \mathrm{C}$. Additionally, this approach is not only very selective towards producing either $\mathrm{Na}_{2} \mathrm{~S}$ or $\mathrm{Na}_{2} \mathrm{~S}_{2}$, but also provides good separation of the $\alpha$ - and $\beta$-phases of $\mathrm{Na}_{2} \mathrm{~S}_{2}$.

High purity anhydrous $\mathrm{Na}_{2} \mathrm{~S}$ was successfully prepared using a simple microwave-assisted heat treatment of a $\mathrm{Na}^{+} / \mathrm{S}$ solution in tetraglyme (see the supporting information). Elemental S and sodium tert-butoxide were dissolved in 1:2 molar ratio in tetraglyme at room temperature (the $S$ concentration was approximately o.1 M). A clear green solution was obtained after stirring in a glovebox for 30 minutes. A $5 \mathrm{ml}$ aliquot of this solution was heated to $200{ }^{\circ} \mathrm{C}$ in a sealed $10 \mathrm{~mL}$ microwave tube for 30 minutes using a CEM Discover SP microwave synthesizer $(2.45 \mathrm{GHz})$. The resulting product was washed thoroughly with THF $(3 \times 3 \mathrm{ml}$ of THF $)$ and finally dried at $100{ }^{\circ} \mathrm{C}$ for $2 \mathrm{~h}$. The washing and drying steps were performed under an argon atmosphere. X-ray powder diffraction (XRD) showed that the as-prepared material is phase-pure, crystalline $\mathrm{Na}_{2} \mathrm{~S}$. No significant change in the XRD pattern was observed when the as-prepared material is calcined at $700{ }^{\circ} \mathrm{C}$ under argon for 1 h. The XRD patterns of the synthesized material, compared to commercial $\mathrm{Na}_{2} \mathrm{~S}$ (anhydrous; Alfa Aesar), are shown in Figure 1. It should be noted that $S$ readily dissolves in tetraglyme only in the presence of sodium tert-butoxide, which suggests that $\mathrm{S}$ likely combines with a Na-tetraglyme complex ${ }^{6}$ to form a soluble (green colored) complex compound which subsequently decomposes by microwave-assisted heating to $\mathrm{Na}_{2} \mathrm{~S}$. A microwave heat treatment is essential here, because the reaction could not be achieved by conventional heating in a Teflon lined autoclave.

Our synthetic approach also proved successful in synthesizing phase-pure $\mathrm{Na}_{2} \mathrm{~S}_{2}$ (in the form of a mixture of $\alpha$ and $\beta$ polymorphs) simply by varying the reaction temperature. At temperatures below $150{ }^{\circ} \mathrm{C}$, the same sulfur/sodium tert-butoxide solution yields phase-pure $\mathrm{Na}_{2} \mathrm{~S}_{2}$ in the form of a mixture of $\alpha$ (low-temperature) and $\beta$ (high-temperature) phases, with no evidence for the formation of $\mathrm{Na}_{2} \mathrm{~S}$ (see the supporting information). By careful control of the reaction conditions, we could prepare $\alpha$ - and $\beta$-phases with a good separation. Figure 2 shows the XRD patterns of $\mathrm{Na}_{2} \mathrm{~S}_{2}$ obtained after heat treatment of $10 \mathrm{~mL}$ of a $\mathrm{Na}^{+} / \mathrm{S}$ solution at 110 and $120^{\circ} \mathrm{C}$. These $\alpha$ and $\beta$ polymorphs are the only phases present, i.e. there are no traces of $\mathrm{Na}_{2} \mathrm{~S}$, demonstrating the high selectivity of our synthesis method. Additionally, we clearly observe that $\alpha-\mathrm{Na}_{2} \mathrm{~S}_{2}$ 
predominates in the material prepared at $110{ }^{\circ} \mathrm{C}$, while $\beta-\mathrm{Na}_{2} \mathrm{~S}_{2}$ predominates in the material prepared at $120{ }^{\circ} \mathrm{C}$, indicating good separation of the two polymorphs. At higher treatment temperatures $\left(>150^{\circ} \mathrm{C}\right)$, we begin to see the emergence of $\mathrm{Na}_{2} \mathrm{~S}$ together with $\alpha-\mathrm{Na}_{2} \mathrm{~S}_{2}$ (see Figure $\mathrm{S}_{1}$ ). A mixture of $\mathrm{Na}_{2} \mathrm{~S}$ and $\mathrm{Na}_{2} \mathrm{~S}_{2}$ is also generally obtained when the $\mathrm{S} / \mathrm{Na}$ in the initial $\mathrm{S} / \mathrm{Na}^{+}$solution is changed from 1:2 (e.g. to 1:1), indicating that the $1: 2$ ratio is probably critical to obtain a complex compound that decomposes to either $\mathrm{Na}_{2} \mathrm{~S}$ or $\mathrm{Na}_{2} \mathrm{~S}_{2}$ depending on the temperature.
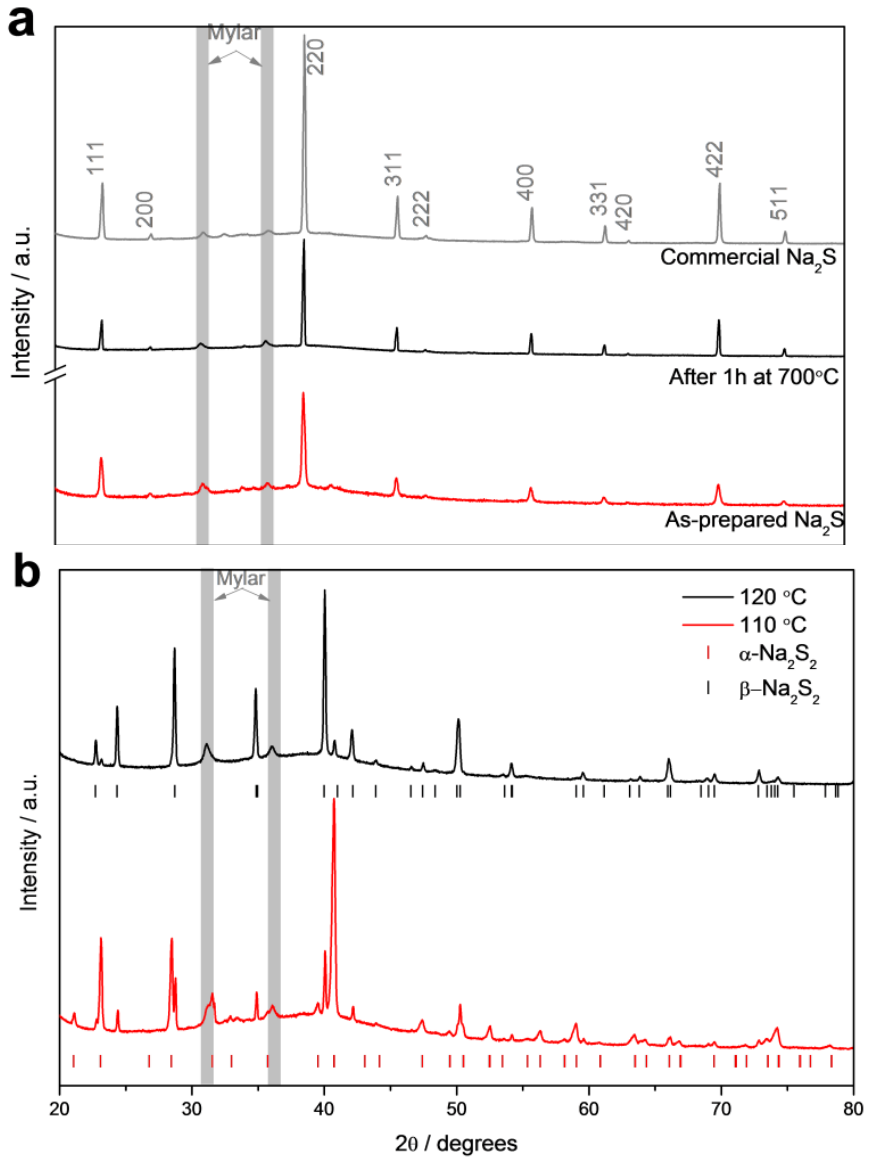

Figure 1. a) XRD patterns of as-prepared $\mathrm{Na}_{2} \mathrm{~S}, \mathrm{Na}_{2} \mathrm{~S}$ after calcination at $700{ }^{\circ} \mathrm{C}$ for 1 h under argon compared with commercial $\mathrm{Na}_{2} \mathrm{~S}$ (Alfa Aesar). b) XRD patterns of $\mathrm{Na}_{2} \mathrm{~S}_{2}$ prepared at 110 and $120{ }^{\circ} \mathrm{C}$, showing a predominance of the $\alpha$-phase (PDF o1-089-2751 81-1771) at $110{ }^{\circ} \mathrm{C}$, while the $\beta$-phase (PDF o1-o892753 29-793) predominates at $120{ }^{\circ} \mathrm{C}$. The powder materials were sealed in an airtight XRD sample holder (with a Mylar window) in an argon filled glovebox to prevent reaction with moisture.

Hence our approach provides a facile, selective and fast approach to prepare phase-pure $\mathrm{Na}_{2} \mathrm{~S}$ and $\mathrm{Na}_{2} \mathrm{~S}_{2}$. This approach is cost-effective and provides a safer alternative by avoiding the use of Na metal or liquid ammonia. The material morphology was examined by scanning electron microscopy (SEM, also see Figure $\mathrm{S}_{2}$ ). Figure 2 shows that $\mathrm{Na}_{2} \mathrm{~S}$ and $\alpha-\mathrm{Na}_{2} \mathrm{~S}_{2}$ prepared at $110{ }^{\circ} \mathrm{C}$ are formed of solid spheres with typical diameters of between $1 \mu \mathrm{m}$ and $2 \mu \mathrm{m}$. Interestingly, the morphology of $\beta-\mathrm{Na}_{2} \mathrm{~S}_{2}$ (prepared at $120{ }^{\circ} \mathrm{C}$ ) is significantly different, showing agglomerated, large hexagonal-shaped crystals as the main morphological feature.
Recent research on Na-based batteries as a low-cost alternative to Li-batteries has seen a considerable focus on the development of room-temperature Na-S batteries ${ }^{7-16}$ which can employ sodium sulfide/polysulfides as positive electrodes. ${ }^{13-16}$ The use of a sodiated cathode, such as $\mathrm{Na}_{2} \mathrm{~S}$ or $\mathrm{Na}_{2} \mathrm{~S}_{2}$, allows the application of sodium-free anodes, such as hard carbon, $\mathrm{Si}$ and Sn. This improves the safety features of the battery and may also reduce capacity fade which can result from the reaction between Na-metal anodes and the polysulfide ions migrating from the cathode. This shuttling effect of polysulfide ions in $\mathrm{Li} / \mathrm{Na}$-sulfur batteries, in addition to the insulating nature of the sulfur electrode itself and severe volume changes associated with $\mathrm{Na}^{+}$or $\mathrm{Li}^{+}$(de)insertion process, are persistent issues that result in deleterious capacity fading on cycling and preclude the more widespread development of these battery chemistries. ${ }^{7-16}$ Room temperature Na-S batteries face even more serious challenges associated with the sulfur active material, the inherent capacity fade during cycling and their short lifespan. 7,8 This is due to more sluggish electrochemical activity, rapid polysulfide migration, potential vigorous reactions between the $\mathrm{Na}$ anode and $\mathrm{Na}_{2} \mathrm{~S}_{\mathrm{n}}$ species, and even greater volume changes in the sulfur electrode. Batteries employing Na-free anodes and sodiated cathodes (e.g. $\mathrm{Na}_{2} \mathrm{~S}$ and $\mathrm{Na}_{2} \mathrm{~S}_{2}$ ) are expected to exhibit better performance. For example, employing $\mathrm{Na}_{2} \mathrm{~S}_{2}$ as a cathode and a $\mathrm{Na}$-free anode would eliminate the potential solid-solid $\mathrm{Na}_{2} \mathrm{~S}_{2} / \mathrm{Na}_{2} \mathrm{~S}$ conversion step which, due to the nonconductive nature of $\mathrm{Na}_{2} \mathrm{~S}_{2}$ and $\mathrm{Na}_{2} \mathrm{~S}$, is kinetically slow and suffers from high polarization. ${ }^{12,13}$

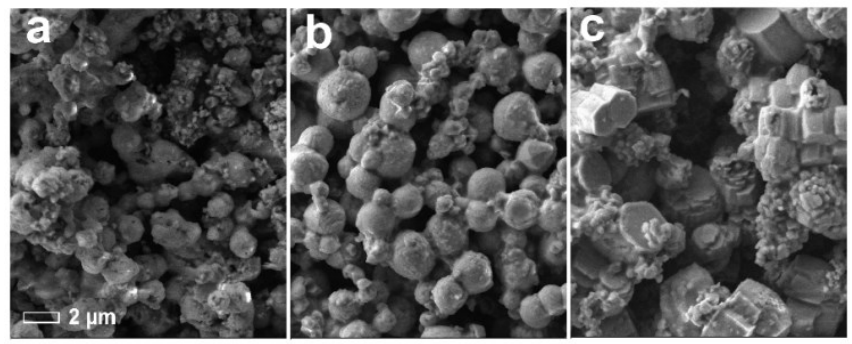

Figure 2. The morphology of as-prepared $\mathrm{Na}_{2} \mathrm{~S}(\mathrm{a}), \mathrm{Na}_{2} \mathrm{~S}_{2}$ prepared at $110{ }^{\circ} \mathrm{C}$ (b) and $\mathrm{Na}_{2} \mathrm{~S}_{2}$ prepared at $120{ }^{\circ} \mathrm{C}$ (c). Scale bar of $2 \mu \mathrm{m}$ is for all figures.

To assess the electrochemical activity of our materials, we have applied them as positive electrodes in Na-S batteries using $\mathrm{Na}$ metal as the negative electrode and 1.5 $\mathrm{M} \mathrm{NaClO}_{4} / \mathrm{o.} .3 \mathrm{M}$ $\mathrm{NaNO}_{3}$ in tetraglyme as the electrolyte. The active material was simply mixed with conductive carbon and a PTFE binder (in 6:2.5:1.5 weight ratio) and pressed in a thin pellet $(\sim 3 \mathrm{mg})$. Our procedure is not suitable to evaluate the cycle performance of these batteries, since no precautions are undertaken to avoid deleterious shuttle activity and this is beyond the scope of our current paper. ${ }^{15,16}$ Our aim here is to evaluate the electrochemical activity and initial utilization of the active species for each of the materials we have synthesised. The electrochemical activity of $\mathrm{Na}_{2} \mathrm{~S}_{2}$ has not been previously reported independently, most likely due to the difficulties in obtaining sufficiently pure material. Figure za shows representative cyclic voltammograms (CVs) for the three materials: $\mathrm{Na}_{2} \mathrm{~S}$, $\beta-\mathrm{Na}_{2} \mathrm{~S}_{2}$ and $\alpha-\mathrm{Na}_{2} \mathrm{~S}_{2}$. The large oxidation peak in the first cycle corresponds to the removal of $\mathrm{Na}^{+}$from the cathode and this peak appears at a slightly higher potential for $\mathrm{Na}_{2} \mathrm{~S}_{2}$. After this oxidation process, the CVs for each material displays the typical I-V behaviour of a conventional $\mathrm{Na}-\mathrm{S}$ cell, with two major reduction peaks at $\sim 2.2 \mathrm{~V}$ and $\sim 1.6 \mathrm{~V}$ and two oxidation peaks 
$\sim 1.8 \mathrm{~V}$ and $\sim 2.4 \mathrm{~V}$, indicating the reversible nature of these redox processes. ${ }^{7,8,12-16}$
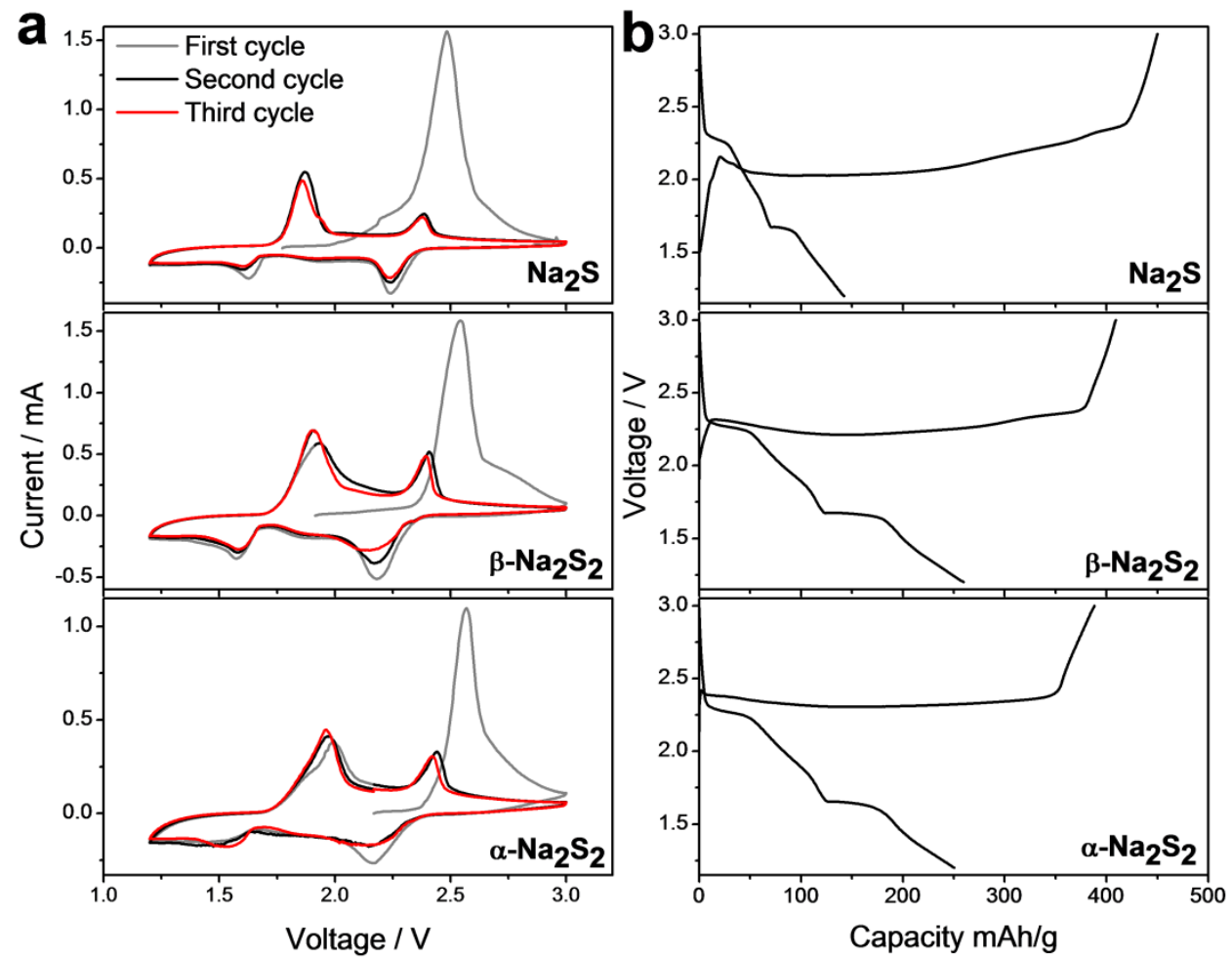

Figure 3. a) Cyclic voltammograms of $\mathrm{Na}_{2} \mathrm{~S}, \beta-\mathrm{Na}_{2} \mathrm{~S}_{2}$ and $\alpha-\mathrm{Na}_{2} \mathrm{~S}_{2}$ at a potential sweep rate of o.1 $\mathrm{mV} \mathrm{s}^{-1}$ between 1.2 and $3.0 \mathrm{~V}$. b) First charge/discharge profiles for each material cycled at $\mathrm{C} / 10$ rate. $1 \mathrm{C}$ corresponds to $687 \mathrm{~mA} / \mathrm{g}$ and $487 \mathrm{~mA} / \mathrm{g}$ for Na $\mathrm{S}_{2}$ and Na $\mathrm{S}_{2}$, respectively.

Figure $3 \mathrm{~b}$ shows voltage profiles of the first charge/discharge for each material. These profiles are consistent with the measured CVs, showing one charge plateau and two discharge plateaus for the first charge and discharge cycle, respectively. Under the applied conditions, initial charge capacities (normalized to the masses of $\mathrm{Na}_{2} \mathrm{~S}$ and $\mathrm{Na}_{2} \mathrm{~S}_{2}$ ) of $\sim 450,410$ and 390 $\mathrm{mAh} / \mathrm{g}$ are observed for $\mathrm{Na}_{2} \mathrm{~S}, \beta-\mathrm{Na}_{2} \mathrm{~S}_{2}$ and $\alpha-\mathrm{Na}_{2} \mathrm{~S}_{2}$, respectively. These correspond to $\sim 65 \%, 84 \%$ and $80 \%$ utilization of $\mathrm{Na}^{+}$in these materials, respectively. These results suggest excellent electrochemical activity of $\mathrm{Na}_{2} \mathrm{~S}_{2}$. In the first discharge, $\mathrm{Na}_{2} \mathrm{~S}_{2}$ also shows higher capacity (normalized to the sulfur content) than $\mathrm{Na}_{2} \mathrm{~S}\left(\sim 44 \mathrm{O} \mathrm{mAh} / \mathrm{g}\right.$ for $\beta-\mathrm{Na}_{2} \mathrm{~S}_{2}$, compared with $\sim 350 \mathrm{mAh} / \mathrm{g}$ for $\left.\mathrm{Na}_{2} \mathrm{~S}\right)$. We could not observe a significant difference in electrochemical activity between $\alpha$ - and $\beta$ $\mathrm{Na}_{2} \mathrm{~S}_{2}$. The slightly higher specific capacity observed for $\beta$ $\mathrm{Na}_{2} \mathrm{~S}_{2}$ is most likely due to the difference in the crystal structure, as well as changes in the particle morphology.

We have demonstrated a new, facile approach for the selective synthesis of $\mathrm{Na}_{2} \mathrm{~S}$ and polymorphs of $\mathrm{Na}_{2} \mathrm{~S}_{2}$. The proposed synthesis is fast, cost effective and avoids the use of Na metal. The synthesis of such highly pure materials has enabled their demonstration as positive electrodes in room-temperature Na-S batteries. Preliminary studies confirm a promising electrochemical activity of $\mathrm{Na}_{2} \mathrm{~S}_{2}$. Optimisation to control the polysulfide shuttle activity and further detailed investigations of these materials is now underway.

\section{ASSOCIATED CONTENT}

\section{Supporting Information}

Supporting information include experimental details, XRD pattern of the sample prepared at $150{ }^{\circ} \mathrm{C}$, and SEM images of $\mathrm{Na} 2 \mathrm{~S}$ calcined at $700{ }^{\circ} \mathrm{C}$. This material is available free of charge via the Internet at http://pubs.acs.org.

\section{AUTHOR INFORMATION}

\section{Corresponding Author}

* serena.corr@glasgow.ac.uk.

\section{Author Contributions}

The manuscript was written through contributions of all authors. All authors have given approval to the final version of the manuscript.

\section{Funding Sources}

This work was supported by funding from the EPSRC (EP/Noo1982/1) and we thank the School of Chemistry at the University of Glasgow for support.

Notes

The authors declare no competing financial interests.

\section{ACKNOWLEDGMENT}

The authors gratefully acknowledge the help and technical support of Mr Michael Beglan and Mr Peter Chung.

\section{REFERENCES}


1 White, J. F. M.; White, A. H. Manufacture of Sodium Sulfide: Reduction of Sodium sulfate to Sodium Sulfide at Temperatures below $800{ }^{\circ} \mathrm{C}$, Ind. Eng. Chem. 1936, 28 (2), 244.

2 G. Brauer, Handbook of Preparative Inorganic Chemistry, 2nd ed., Academic Press, New York, 1963.

3 Degussa, US 4640832, 1985.

4 Yamada, N.; Furukawa, M.; Nishi, M.; Takata, T. Direct Preparation of Anhydrous Sodium Oligosulfides from Metal Sodium and Elemental Sulfur in Aprotic Organic Media Directed toward Synthesis of Silane Coupling Agen, Chem. Lett. 2002, 31, 454.

5 Takata, T.; Saeki, D.; Makita, Y.; Yamada, N.; Kihara, N.; Aromatic Hydrocarbon-Catalyzed Direct Reaction of Sulfur and Sodium in a Heterogeneous System: Selective and Facile Synthesis of Sodium Monosulfide and Disulfide, Inorg. Chem. 2003, 42, 3712.

6 Mandai, T.; Nozawa, R.; Tsuzuki, S.; Yoshida, K.; Ueno, K.; Dokko, K.; Watanabe, M. Phase Diagrams and Solvate Structures of Binary Mixtures of Glymes and Na Salts, J. Phys. Chem. B, 2013, 117 (48), 15072.

7 Wang, Y.-X.; Zhang, B. W.; Lai, W. H.; Xu, Y. F.; Chou, S.-L.; Liu, H.-K.; Dou, S.-X. Room-Temperature Sodium-Sulfur Batteries: A Comprehensive Review on Research Progress and Cell Chemistry, Adv. Energy Mater. 2017, 7, 1602829.

8 Manthiram, A.; Yu, X. Ambient Temperature Sodium-Sulfur Batteries, Small, 2015, 11, 2108.

9 Ghosh, A.; Shukla, S.; Monisha, M.; Kumar, A.; Lochab, B.; Mitra, S. Sulfur Copolymer: A New Cathode Structure for Room-Temperature Sodium-Sulfur Batteries, ACS Energy Lett. 2017, 2 , 2478.
10 Xin, S.; Yin, Y. X.; Guo, Y. G.; Wan, L. J. A High-Energy RoomTemperature Sodium-Sulfur Battery, Adv. Mater. 2014, 26, 1261.

11 Lee, D. J.; Park, J. W.; Hasa, I.; Sun, Y. K.; Scrosati, B.; Hassoun, J. Alternative materials for sodium ion-sulphur batteries, J. Mater. Chem. A 2013, 1, 5256.

$12 \mathrm{Yu}, \mathrm{X}$.; Manthiram, A. Capacity Enhancement and Discharge Mechanisms of Room-Temperature Sodium-Sulfur Batteries, ChemElectroChem 2014, 1, 1275.

13 Yu, X.; Manthiram, A. Highly Reversible Room-Temperature Sulfur/Long-Chain Sodium Polysulfide Batteries, J. Phys. Chem. Lett. 2014, 5, 1943.

$14 \mathrm{Yu}, \mathrm{X}$.; Manthiram, A. Na2S-Carbon Nanotube Fabric Electrodes for Room-Temperature Sodium-Sulfur Batteries, Chem. Eur. J. 2015, 21, 4233 .

$15 \mathrm{Yu}, \mathrm{X}$.; Manthiram A. Ambient-Temperature Sodium-Sulfur Batteries with a Sodiated Nafion Membrane and a Carbon Nanofiber-Activated Carbon Composite Electrode, Adv. Energy Mater. 2015, 5, 1500350.

$16 \mathrm{Yu}, \mathrm{X}$; Manthiram, A. Performance Enhancement and Mechanistic Studies of Room-Temperature Sodium-Sulfur Batteries with a Carbon-Coated Functional Nafion Separator and a Na2S/Activated Carbon Nanofiber Cathode, Chem. Mater. 2016, 28, 896. 
SYNOPSIS TOC. A microwave-assisted approach is used to selectively synthesize $\mathrm{Na}_{2} \mathrm{~S}$ and $\mathrm{Na}_{2} \mathrm{~S}_{2}$ ( $\alpha$ and $\beta$ phases) with high purity and a promising electrochemical activity.
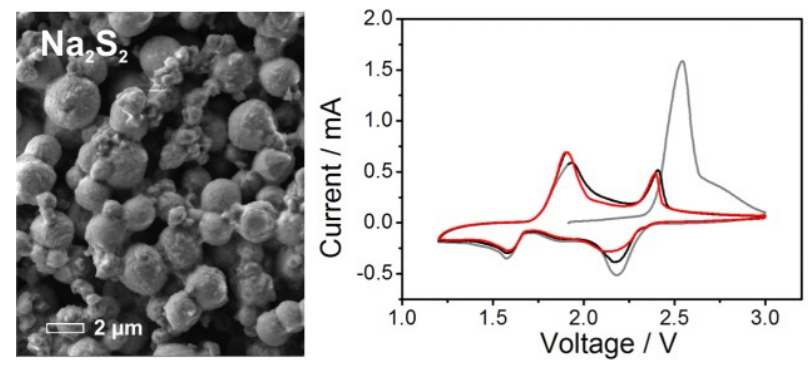